\title{
Conceptual provisions of the implementation of energy saving measures in the residential facilities
}

\author{
Tatiana Meshcheryakova ${ }^{1, *}$ \\ ${ }^{1}$ Moscow State University of Civil Engineering, Yaroslavskoe shosse, 26, Moscow, 129337, Russia
}

\begin{abstract}
Research purpose is identification of sales problems of energy saving actions for residential sector of economy, including with use of the power service contract. The choice of the object of the study is related to the general issues on energy saving of residential facilities and increasing the number of unresolved problems. Unfortunately, the efficiency of energy consumption of housing stock is extremely low that directly leads to an increase in citizens' payments for public utilities (housing and communal services). There are many problems associated with the aging of fixed assets: it becomes especially evident in winter seasons. The level of quality of delivery, distribution and consumption of expensive heat resources that has the greatest impact on a residence comfort and sometimes human life and health, is very low. Our population faces to year overheating or freezing, to leakages through worn pipes and the subsequent disconnection of water and heat. Despite the public declaration of the of the active processes of modernization of the housing municipal economy in the Russian Federation, the implementation of the necessary energy-saving elements in the housing sector is evolving very slowly. The article presents conceptual positions, which will bring the issues related to energy saving and efficiency to a new level.
\end{abstract}

\section{Introduction}

State-owned enterprises and private companies in order to remain competitive, as well as in the interests of certain economic activities at the level of the national economy, should reduce energy costs at a steady or growing level of efficiency.

Energy saving and energy efficiency of operated facilities allow not only achieve the goals which were formulated by the government in the frame of national interest, but also qualitatively improve the business and societal benefits [1].

Review of the implementation of energy conservation and energy efficiency needs to investigate the investment component. Achieving core results in the problems it is possible when we using complex approaches and it often assumed considerable investments.

In this context, we must find partners, who is interested in the implementation of energy saving measures, and partners, who is able to sustain the measures with funding.

\footnotetext{
*Corresponding author: t.meshcheryakova@mail.ru
} 
Stakeholders are those who exploit the object and make payments for consumed energy that is, there can be each user (an individual, an enterprise, and the state if it partially subsidizes the energy costs). However, the financing of energy efficiency measures is not always possible by stakeholders. The particular consumer is not always ready to bear the capital costs of the implementation of high-risk energy saving projects of and energy efficiency enhancing facilities that are always highly expended. Such risks are associated with the multivaluebility of the problem field: difficulties with prediction of the expected results of the measures, unforeseen circumstances during the technical work in energy systems and the lack of controlled processes in carrying out these energy-saving activities and procedures. . With regard to the state budget in the financing of energy-saving measures, it should be noted that the amount of funding from the state for this purpose is reduced every year. Given below the analysis of official documents of the Ministry of Energy of the Russian Federation shows that the total volume of investments in energy saving measures is reduced from year to year and in 2015 decreased by $28 \%$ compared to the previous. Data for 2016 and the beginning of 2017 are not reflected in official documents, however, the current trend of reducing investments is maintained. This situation is largely due to fundamental economic factors, the overall turbulence of the financial markets and the current budgetary constraints.

At the circumstances of the finance restrictions the methods of energy service contracts have a special meaning in the energy saving projects.

An energy service contracts (ESC) or a performance contract (EPC) embodies one of the most important energy-saving mechanisms, aggregating a following up investment and implementation components. This lever of necessary investments that shall be compensated by means of guaranteed cost savings due to energy saving (reducing energy consumption).

This tool has a positive practice in many countries and has gained recognition at the political level in the Russian Federation. Since the adoption of the Federal Law 261 "On energy saving" (23 November 2009), the energy service contracts have passed through many iterations and applied in different regions from the industry that is the major consumer of energy and that is embodying the greatest potential for energy savings, to residential real estate [2].

There remains a lot of obstacles: the lack of a large-scale public awareness and therefore the necessary knowledge about the energy service contracts, allowing to provide popularization of this instrument at all levels; the absence of effective policies and mechanisms to support energy service contracts; the lack of common definitions and harmonized processes related to energy service contracts.

The article deals with problems of implementation of energy-saving measures for the residential sector of the economics, including the use of energy service contracts. The choice of the object of the study is related to the general issues on energy saving of residential facilities and increasing the number of unresolved problems. Unfortunately, the efficiency of energy consumption of housing stock is extremely low that directly leads to an increase in citizens' payments for public utilities (housing and communal services). There are many problems associated with the aging of fixed assets: it becomes especially evident in winter seasons. The level of quality of delivery, distribution and consumption of expensive heat resources that has the greatest impact on a residence comfort and sometimes human life and health, is very low. Our population faces to year overheating or freezing, to leakages through worn pipes and the subsequent disconnection of water and heat. Despite the public declaration of the of the active processes of modernization of the housing municipal economy in the Russian Federation, the implementation of the necessary energysaving elements in the housing sector is evolving very slowly.

The article presents conceptual positions, which will bring the issues related to energy saving and efficiency to a new level. 
The existing power system in the world is the great legacy of the past. It became the basis for the industrial recovery, development of new territories, raising the quality of people life to a new level. Recently, however, there have been changes, forcing to reconsider the requirements for infrastructure, electric power facilities, energy markets: in industry there is growing depreciation, which requires considerable investments into the modernization of existing power equipment, replacement of decommissioned facilities and the construction of new ones; in the housing sector there is the necessary energy saving measures which determine a reduction in energy costs while increasing the needs for the level of accommodation comfort; in the transport sector there is a reduction of fiscal burden in the operation of transport infrastructure $[3,4]$.

The legislation on energy emerged in the late 1990s. Since then, efforts to save energy is slowly developing in Russia. It is still a low level of energy efficiency in the production, distribution and consumption of energy/ Together with a harsh climate it gives a low energy use coefficient that is 3-5 times lower than in Western Europe as a result [5].

One of the key background documents is adopted in 2008 "On some measures to improve the energy and environmental efficiency of the Russian economy" Presidential Decree number 889 , which was defined goal to reduce the energy consumption of gross domestic product by $40 \%$ from 2007 to 2020 .

For these purposes the decree prescribes:

- To take measures on technical regulation in sectors of the economy aimed at improving the energy and ecology efficiency;

- Prepare the legal framework at the level of federal laws imposing economic mechanisms to encourage use energy-saving technologies and forming responsible for failure in complying with accepted standards;

- Provide budgetary allocations for the implementation of energy saving projects [6,7].

For the execution of the Decree of the President on 23 November 2009 there was emerged the Federal Law № 261-FZ "On energy saving and energy efficiency improvements and on Amendments to Certain Legislative Acts of the Russian Federation" (Federal Law "On energy saving") that aims to create the legal, economic and organizational basis to stimulate energy savings and energy efficiency. There was the first to define the terms of compulsory installation of meters, their commissioning and going to energy payments for actual consumption. For budget institutions there tasked the decrease of volume of consumed energy in comparable conditions at least $15 \%$ of the amount actually consumed in 2009 for five years, with an annual reduction of the amount not less than $3 \%[6]$.

To achieve these objectives there was adopted the state program "Energy saving and energy efficiency for the period till 2020", approved by the Federal Government in 2010.

One of the mandatory directions of development of energy-efficient economy is the ESC. In the European Union, ESC is used from the 1980s. Nevertheless, the market is still underdeveloped, especially compared with the United States and Canada. ESCO model, actively reproducible in both the European Union and at the wide international level (including Russia), the principle of the use of the warranty, cost-effective and scalable systems of reducing of operating costs and reducing of negative impacts on the environment objects property there was designed as the core concept to use. ESC is a proven tool used in Austria, Germany, Czech Republic and Scandinavia, to a certain extent implemented in the United Kingdom and France, but it is almost never used in other countries of the European Union [7].

The content and significance of the ESC mechanism defined in the Federal Law "On energy saving", as well as in the Draft Energy Strategy-2035. This type of a contract allows mastering new technologies and equipment in the field of energy saving and for significant energy savings by a customer company. All the costs, including design, purchase; 
installations, and assembling of the equipment, are paid by the implementing organization (ESC) in the frame of an energy service contract at the cost of own and borrowed funds only when the required level of energy saving on the customer's facilities is reached. In this way, all costs incurred by the energy service company during implementation of the project lays in the cost of energy service works, but they returned as a profit from the assets received of the funds received as a result of the energy savings by the customer. The main objectives of this contract are down to the following: carrying out an energy audit to control the definition of the baseline power consumption, the introduction of new mechanisms of energy saving technologies; testing, monitoring, and billing of the project, as well as in some cases, post-project maintenance. Signing of an energy service contract allows the customer to provide the effect of resource saving due to the following:

1. The reduction of funds spent on the generation and supply of resources (heat, electricity, gas, water);

2. The reduction of the volume of resource consumptions;

3. The improvement of production processes in organizations;

4. The reduction of funds spent on the fix and maintenance of equipment.

Despite the urgency of these issues, the analysis of official data of the Ministry of Energy, contained in the annual State report on the state of energy saving and energy efficiency in the Russian Federation, shows a significant reduction of all forms of investments in energy saving measures (Figure 1) [8].

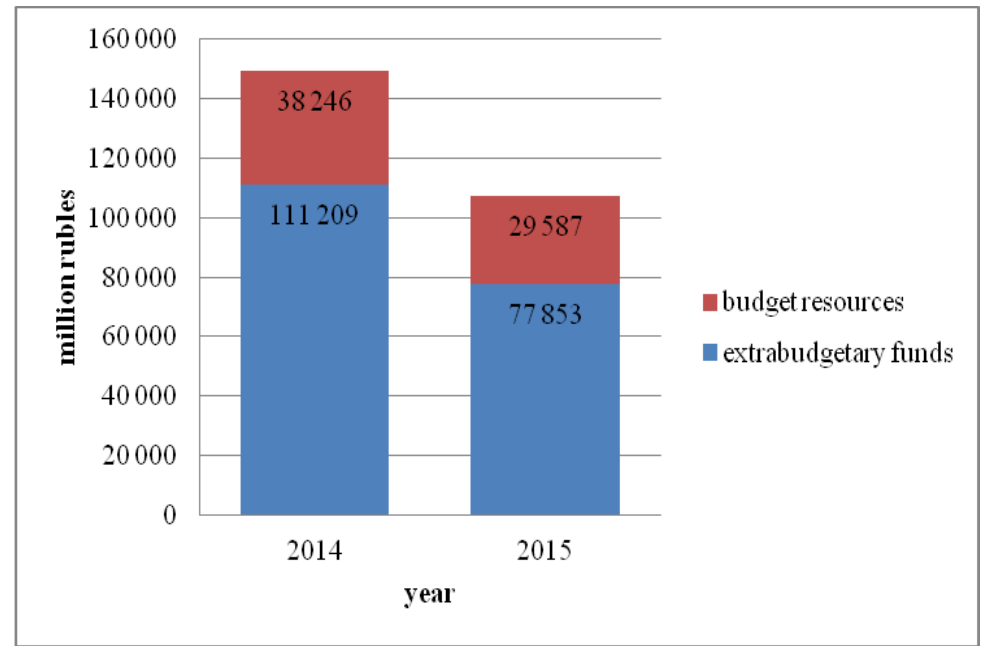

Fig. 1. Investments in energy efficiency measures (the chart compiled on the basis of data provided by the State Department of Energy report on the status of energy saving and energy efficiency improvements in the Russian Federation in 2015).

Currently, the Russian Federation is experiencing some economic problems in foreign markets. Problematic economic phenomena must not be interfering with the development of energy services and counteract it. In the current economic conditions which determine the development of the issue import substitution industrialization, it is necessary to find the ways for implementation of technical solutions in the field of energy saving. In addressing this issue it is important to take into account the interests of a customer, since any energy service contract in the Russian Federation currently has a local character, and to ensure that the planned project/ It is possible only when the required level of interactions between all subjects that provides reliable information for monitoring of power systems at each stage of the implementation of an energy service contract. 
The main region of the development of energy services by the municipalities the majority of subjects who are actively involved in the implementation of the sub-program "Energy saving and energy efficiency" as part of the current program "Energy Efficiency and Energy Development" is the sphere of housing and communal services. Municipalities play a huge role in the development of energy service contracts. Their main initiatives are creation an interagency working group to support of projects on energy saving and energy efficiency together with the Ministry of Energy, are showing the results of this group at the annual international forum on energy saving and are summarizing these results concerning the communal services modernization and the implementation of energy service contracts. It allows the most effective using of budget funds implementation and development of balanced scorecards, which will be focused on the end results.

Measures of state regulation in the sphere of energy saving and energy efficiency, included in the Federal Law "On energy saving", which are directly aimed at ensuring the rational use of energy resources in the housing, can be divided into several groups:

- The first group of steps of state regulation is aimed to establishing requirements on the implementation of organizational actions before the energy saving and energy efficiency measures. Implementation of these steps will not lead to immediate savings of energy and water or improve the efficiency of their use, but it is a necessary prerequisite for the development of a system of measures aimed at implementing the technological potential of energy saving and energy efficiency. These steps include: the obligation to use the account of power resources; requirements for energy audits.

- The second group of government regulation steps is associated with the use of the software to solve the problem of energy saving and energy efficiency in the housing stock and includes the following: the requirements for regional and municipal programs in the field of energy saving and energy efficiency; requirements for the program in the field of energy saving and energy efficiency organizations engaged in regulated activities.

- The third group of steps of state regulation is ensuring the realization of technical measures for energy saving and energy efficiency augmentation in the housing stock. Some of these steps include: the requirements of the energy efficiency of buildings, structures and facilities; obliging on the energy saving and energy efficiency of the common property for the owners of premises in an apartment building.

- The fourth group of steps of state regulation covers a range of ensuring measures to encourage the rational use of energy resources in the housing sector. In this case we are talking about steps such as: information support of energy saving measures and energy efficiency; state support for energy saving and energy efficiency augmentation $[9,10]$.

\section{Methods}

In accordance with Article 12 of the Federal Law "On Energy Saving", those, who responsible for the contents of the apartment building, are obliged to conduct measures on energy saving and energy efficiency augmentation. In order to reduce the cost of these measures, the owners of premises in an apartment house shall be entitled to require from the person, responsible for the contents of the apartment building, to implement actions aimed to reducing the volume used in the apartment building energy resources $[11,12]$.

Taking the second largest energy end-use in Russia, the housing sector has a great potential for energy savings. Implementing energy efficiency measures in the housing sector will also help to save an additional amount of energy due to the multiplier effect (concomitant reduction of primary energy consumption).

The level of energy efficiency of buildings is influenced by many different organizations involved in the construction, management and maintenance of buildings. 
They all have the opportunity to influence the energy consumption inside buildings, but few have stimuluses to change anything. Those who might have such stimuluses, worst of all are aware of what actions can lead to energy savings, and even if they know it but not are able to pay or to fund these activities. The main barriers to the development of projects on energy saving and energy efficiency augmentation for residential buildings, are inherent for Russia and include the following:

- Low energy resources tariffs for the population;

- The lack of effective monitoring of compliance with existing standards for new buildings;

- Lack of awareness of energy efficiency among homeowners that ultimately determines their behavior.

It should be noted that the barriers and solutions for various types of buildings are different. Three groups can be distinguished:

a) buildings under construction;

b) buildings in the stage of reconstruction or main refurbishing;

c) exploited buildings.

Removing barriers in the housing sector requires, firstly and foremost, ensuring compliance with building energy efficiency standards. Additional benefits can be obtained by improving the data collection in residential buildings on energy consumption, and dissemination of information among homeowners. It is also possible to use one of the most effective alternatives, that are ESC that mentioned above.

The aggregative scheme of implementation of energy saving measures initiated by the consumers of energy, is presented in Figure 2.

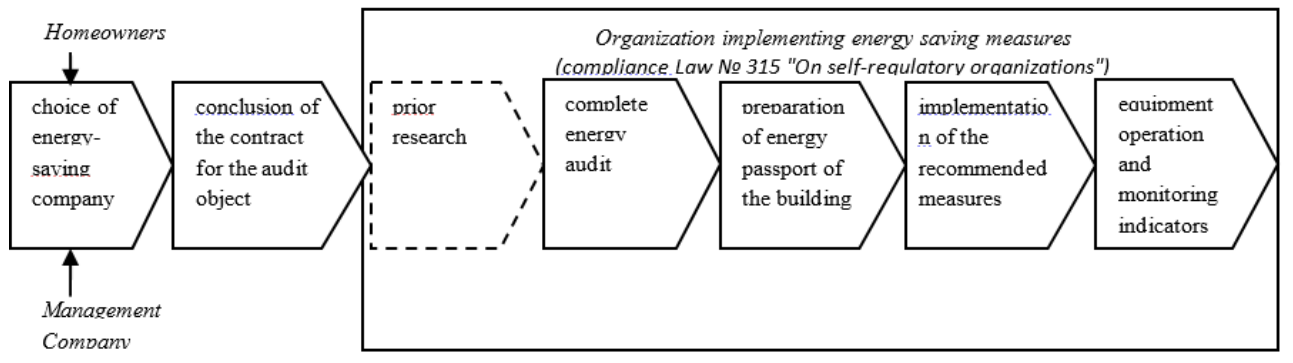

Fig. 2. Implementation of energy saving measures.

Currently there are several special kinds of ESCs in the domestic legislation, which have a special legal regulation:

- State or municipal ESC concluded for state or municipal needs;

- ESC aimed at saving and (or) increase the efficiency of consumption of resources by the common properties;

- Contracts for the sale, supply, transfer of energy resources, including ESC conditions $[13,14]$.

The RF Government Decree dated by August 23, 2010 № 646 approved the formation principles for the lists of energy conservation measures and energy efficiency augmentation in relation to the common property of the owners of premises in an apartment building.

According to the principles stated in the Resolution, the executive authorities of the Russian Federation form the list of measures in respect to the common property of the owners of premises in apartment buildings. Principles of formation of the list of measures include fulfillment of the obligations to update the technical solutions for the mandatory activities, at least 1 time in 3 years, besides argumentation in their economic viability. As a Contractor ESC may be the organization engaged in energy resources supply of apartment buildings on the basis of a public contract. In doing so, the organization regularly (at least 
once a year) is required to provide a list of activities for an apartment building or for a group of houses, which are in the common property of the owners of premises in an apartment building, holding, to a greater extent, energy saving in respect to premises in an apartment building. It promotes saving of the energy resources supplied by this organization in the apartment building and energy efficiency augmentation of their use.

In accordance with the Rules of maintenance of the common property in an apartment building, approved by Decree of the Government of the Russian Federation dated August 13, 2006 № 491, owners of premises have the right to take a decision on the conclusion of ESC for the common house needs with a management company, homeowners, housing, housing building societies or other specialized consumer cooperative, or to allot the said ones or any partnership, or cooperative authority by the right to conclude ESC on the general needs of the house with the organization providing energy services. In this case, the general needs of the house refers to all activities aimed at saving and (or) increase the efficiency of municipal resource consumption using the common property, the composition of which is determined in accordance with the Rules of the maintenance of the common property in an apartment building

Exemplary ESC conditions on the common house needs approved by the order of the Ministry of Regional Development of the Russian Federation on June 27, 2012 № 252 "On Approval of the exemplary conditions of an energy treaty aimed at saving and (or) increase the efficiency of public services consumption using the common property in an apartment house"

In practice, according to a contract on energy service by ESC, it is delivered a complex reconstruction of the building, which may include the replacement of boilers, insulation, cooling systems, lighting and temperature control automation, and also the integration of software management of energy data and on-site renewable energy systems.

For the formation of the system of motivation of potential participants of ESC, it is necessary to identify the targets of energy saving, both quantitative and qualitative effects for the subjects involved in the implementation of this contract. Therefore it is necessary to form the elements of the incentive system necessary for the successful implementation of the ESC in a variety of subjects:

ESCO's affairs:

- A large amount of energy savings;

- A little payback period;

- High business income;

- The possibility of obtaining long-term benefits.

User's affairs (a consumer of public services):

- The lack of capital expenditures;

- Saving energy resources costs

- Improving building energy efficiency class (at the moment, there is no such motivation in Russia because there is rigid bonds of the immovable property costs with its energy efficiency class);

Managing organization's affairs:

- Compliance with the requirements of normative-legal base in the sphere of energy saving and energy efficiency, including compliance with the requirements of energy efficiency of buildings, structures and facilities (approved by the Order of the Ministry of Regional Development of the Russian Federation by May 28, 2010 № 262) and implementing regulations "On approval of certain rights class energy efficiency of apartment buildings" (approved by the Order of the Ministry of Construction of Russia by June 6,2016 № 399). The exceptions are the objects that are listed in the article 11 of the Federal Law "On energy saving". The requirements of energy efficiency do not apply to the following buildings, structures, constructions: 
1. religious buildings, structures, constructions;

2. buildings, structures, structures that are in accordance with the legislation of Russian Federation referred to the objects of cultural heritage (monuments of history and culture);

3. temporary buildings with a service life of less than two years;

4. objects of individual housing construction (stand-alone and intended for one family, houses with a number of floors not more than three), summer houses, garden houses;

5. auxiliary buildings, structures;

6. stand-alone buildings, structures, facilities, whose total area is less than fifty square meters [2].

In the case of the coordination of interests of all stakeholders, which can be conditionally called "stakeholders of the ESC", because each of them is able to affect the project, it is necessary to develop a unified algorithm for implementation of ESC.

In practice, according to the contract, the ESCO can provide a comprehensive reconstruction of buildings, which may include the replacement of boilers, work on the isolation of various designs and power systems, lighting systems and control automation of temperature regimes, as well as the integration of monitoring software for the data on consumed energy. Also, the use of foreign experience of formation of additional competencies for the ESC is suitable for the most of the projects on the territory of Russia. So, one should consider the need for high-quality energy-saving equipment operation by experts of the company-integrators of power equipment (commission) or advanced training of employees of the management company $[15,16]$.

ESCO carries the project "turnkey" and 8s full responsible for the obtained results, i.e. it covers all aspects of the project from start to finish of the preliminary express energy audits, detailed energy audits, development of recommendations and the formation of Energy Performance, design and engineering, business planning, verification of energy saving measures., installation of energy-saving equipment, commissioning, as well as evaluating the actual effectiveness [5,15].

The list of events includes ESC verifications, (to which there are rarely paid attention in the majority of projects unfortunately, in view of the fact that this component is optional). However, its use ensures high accuracy of the forecast project performance, and as a result, increases its investment attractiveness. In the case of understanding the needs for verification of energy efficiency, you can use the unified Standard SRT 001-2014, approved by the Council «RAESKO» of Association of Energy Service Companies [17].

Four methods are given in the Standard for determining the savings (A, B, C and D). The choice of method is determined by a number of factors, including the factor that will host the measurement boundary. If it is decided to determine savings at the facility level, the preferred methods may be $\mathrm{C}$ or D. However, if the subject of performance indicators are only an individual energy-saving measures, it should chose the methods of separate modernization chosen (Methods A, B or D) [17].

The choice of method is done by the developer of the plan of measurement and verification of energy efficiency for each project on the basis of a full set of baseline data, analysis of the existing financial possibilities and their professional opinions. Figure 3 shows the general logic for the choice of the Method.

It should be noted that the study does not address the properties of individual properties, because such buildings energy saving and energy efficiency augmentation through the provision of energy services is difficult. It should be understood that if the object is a lowfloor residential private property, then in this case the owner can carry out energy-saving measures, involving the organization only on the basis of works contracts for its own account. Energy company focused on the projects for starting from the mid-floor buildings and often is interested in high-rise, higher-rise and highest-rise residential buildings. 


\section{Results}

The main results and conclusions of the study are as follows:

- There are a number of barriers in the housing sector, hindering the implementation of energy saving and energy efficiency policy. Firstly, the apartment owners and management companies are still not known with the methods to improve energy efficiency. Secondly, developers and their contractors have no incentives to improve energy efficiency (this applies to constructed sites). Thirdly, there are access restrictions for the owners of apartments, condominiums, management companies to external funding. Fourth, it is abolished the obligation to comply with the Standards of thermal protection of buildings (voluntary since 2010). Measures to eliminate these barriers are: dissemination of information on energy efficiency; compliance with mandatory minimum acceptable requirements of energy efficiency standards for buildings, maintenance of energy certificates for energy efficiency monitoring during the life of the buildings; provision of financial support from the government to carry out repairs; continuation to stimulate the installation of metering devices; development of model performance contracting or ESC on building management for HOAs and management companies: the establishment of the fund, which provides guarantees for loans to carry out repairs to increase the energy efficiency of buildings $[18,19]$. One of the main mechanisms for the implementation of energy saving measures in the current economic environment is an ESC. The ESCO acts as chief project manager, often attracts other partners or contractors to carry out certain works, retaining overall responsibility for performance and energy savings guaranteed. In addition, the most important for this model is that the ESCO takes the performance risk (concerning the effectiveness of the project) in the form of long-term financial guarantees to ensure that the targets of reducing operating costs, materializing and continuing for a long time. If the planned energy savings are not achieved, the ESCO takes the obligation to pay the difference between the actual and planned savings level.

- An important result of the study is development of an verification algorithm of energy efficiency based on "Rae" of the Association of Energy Service Companies methodology and copyright methodical approach to the rationale of economic efficiency embodiment of the energy-saving measures with the use of real options theory. This approach allows us to summarize the existing experience, embodied in standardized documents and the author's development of economic and mathematical calculations of the effects of the implementation of energy saving measures, which take into account the risks of noncompliance of actual and planned results obtained after carrying out energy efficiency measures as part of ESC.

\section{Discussion}

The energy saving perspective determined in a research in the sphere of housing and communal services is important for implementation of the subprogramme "Energy saving and increase in energy efficiency" as a part of the state program "Energy efficiency and development of power". The conceptual approach developed by the author can be a methodical element in case of implementation of a key national objective in the specified subprogramme, namely: stimulation of attraction of off-budget investments in implementation of actions (projects) in the field of energy saving and increase in energy efficiency. Implementation of energy saving actions by the author is offered via the mechanism of the energy service contract which economic correctness is proved, including with use of an algorithm of verification of energy efficiency. Difficulties of a research are that the unified methodical basis for implementation of energy saving actions in apartment residential buildings isn't created yet, and all provisions have advisory nature. Also it is 
necessary to consider that all issues of energy saving can't effectively be resolved until not yet finalized design federal regulating documents which are connected with tariff regulation and establishment of requirements to installation of thermal counters and regulators of heat energy for buildings according to horizontal and vertical distributing of pipelines.

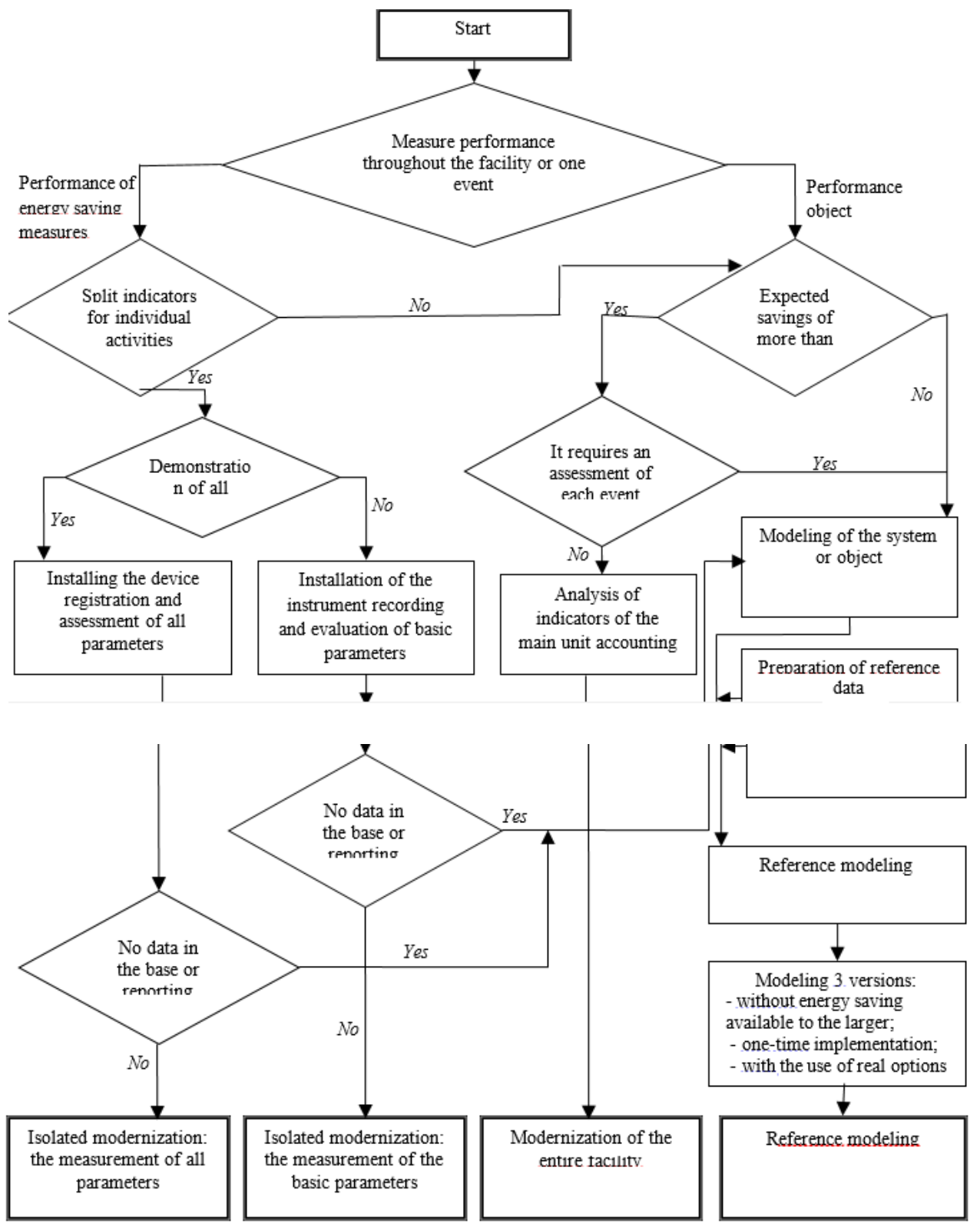

Fig. 3. The algorithm of a selection method for verification of energy efficiency.

\section{Conclusions}

The main barrier to the widespread use of ESC mechanism in Russia is the lack of longterm funding for engineering companies and energy service companies with low 
capitalization. Energy service is a new mechanism by which commercial banks are badly or unfamiliar and under which they are not prepared to provide ESCO loans at this stage secured solely by the funds that are generated at the facilities by saving resources. In small and medium engineering companies no ability to attract project financing or long-term credit resources due to the high assessment of credit risk of such companies by commercial banks and the relevant requirements of the latter to provide significant liquidity support. At the same time, large engineering companies capable of attracting long-term credit facilities, are not ready to take on their balance sheets more debts for the implementation of energy projects (with payback periods of 3 - 7 years) because of the limited capacity to issue corporate guarantees for such loans. Typically, corporate guarantees backed up by companies for the financing of traditional construction and engineering contracts with a payback within 2 - 3 years. Thus, there is currently no financial player, ready to take the non-payment risks in long-term projects, and the potential performers (ESCO) have no long-term capital for this purpose. To summarize, it should be noted that it is necessary to develop stimulus for the energy savings for all market participants. If at least one of the participants of the market will be unprofitable, there will be no overall success. In addition, the most important thing - it is necessary to develop energy-saving strategy for all market participants.

\section{References}

1 Presidential Decree № 889, Rossiyskaya gazeta, 4680 (2008)

2 Federal Law of the Russian Federation № 261-FZ, Rossiyskaya gazeta, 550 (2009)

3 BP Energy Outlook 2035 (BP p.l.c., London, 2015)

4 Plan of activities of the Ministry of Energy of the Russian Federation in 2016-2021, 450 (2016)

5 Eu.bac., About EPC European Building Automation and Controls Association (2016)

6 Ministry of Energy of the Russian Federation, General provisions (2015)

7 A. Mottaeva, MATEC 73, 07020 (2016)

8 State report power saving and increasing energy efficiency in the RF (2016)

9 G.N. Ivanov, Energosovet 02, 15 (2011)

10 T.A. Verminskaya, V.Sh. Zinatullin, A.V. Kukhta, I.V. Rubtsov, E.Yu. Chibisova, Almanac of modern science and education 07, 37-39 (2008)

11 PLS «TEKO-ltd», Energosovet (2007)

12 A. Pimenova, S. Kuzmina, N. Morozova, A. Mottaeva, MATEC 73, 07018 (2016)

13 Technique of involvement of power service companies in modernization of regional housing stock (Analytical Center Government of the Russian, Moscow, 2014)

14 A. Mottaeva, A. Zheltenkov, I. Stukanova, S. Ryabichenko, S. Zhuk, MATEC 73, 07026 (2016)

15 T.S. Mescheryakova, Economy and entrepreneurship, 01, 617-620 ( 2015)

16 A.V. Zinatullin, E.Y. Chibisova, Strategy of sustainable development of regions of Russia 5, 324-328 (2011)

17 Measurement and verification of energy efficiency (RAESKO, Moscow, 2014)

18 N.G. Verstiva, T.S. Mescheryakova, Biosciences Biotechnology Research Asia 01, 617-620 ( 2015)

19 T.S. Mescheryakova, AVOK Energy savings 05, 54-57 (2016) 